ISSN: 0213-2060

DOI: https://doi.org/10.14201/shhme2018362149170

\title{
EL HEREDAMIENTO DE DARALGAZI: UNA PROPIEDAD ARISTOCRÁTICA EN LA VEGA DE GRANADA ${ }^{1}$
}

\section{The Inheritance of Daralgazi: an Aristocratic Property in the Vega of Granada}

\author{
Sandra SUÁREZ GARCÍA \\ Depto. de Historia Medieval y Ciencias y Técnicas Historiográficas. Facultad de Filosofía y Letras. Universidad de \\ Granada.Campus Universitario de Cartuja.E-18071 GRANADA. C. e.: sandrasuarez@ugr.es
}

RESUMEN: Analizamos las características del heredamiento de Daralgazi, ubicado en la Vega de Granada, que recibe Sancho de Castilla de los Reyes Católicos en 1494, a través de una merced otorgada por sus méritos en la Guerra de Granada. Daralgazi constituye una propiedad que pasa de los bienes de las «reinas moras» a manos de los monarcas castellanoaragoneses en el contexto de las capitulaciones. Nos centramos en las características de la propiedad, la mención de la misma en otro tipo de fuentes, su naturaleza y ubicación. Todo ello inserto en el debate del cambio de propiedad aristocrática en el periodo de conquista.

Palabras clave: Daralgazi; Propiedad; Aristocracia; Reino de Granada; Almunia; Conquista.

ABSTRACT: In this essay we will analyze the characteristics of the inheritance of Daralgazi, located in the Vega of Granada, which Sancho de Castilla receives from the Catholic Monarchs in 1494, through a mercy granted for his merits in the War of Granada. Daralgazi is a property that passes from the holding of the «Moorish queens» to the hands of the Castilian-Aragonese monarchs during the time of the capitulations. We will focus on the characteristics of this property, the mention of it in other kinds of sources, and their nature and location. To sum up, all this topic will be inserted in the debate of the change of aristocratic property in the period of Conquest.

Keywords: Daralgazi; Property; Aristocracy; Kingdom of Granada; Almunia; Conquest.

1 Este artículo se inscribe dentro del proyecto de $\mathrm{I}+\mathrm{D}$ «La propiedad aristocrática en la Granada nazarí y su traspaso a la sociedad castellana después de la conquista (siglos XIII-XVI)» (HAR2015-64605-C2-2-P) de la Universidad de Granada, del que la autora es investigadora gracias a la ayuda para contratos predoctorales del Ministerio de Economía, Industria y Competitividad. 
EL HEREDAMIENTO DE DARALGAZI: UNA PROPIEDAD ARISTOCRÁTICA EN LA VEGA DE GRANADA SANDRA SUÁREZ GARCÍA

150

SUMARIO: 0 Introducción. 1 Acerca del patrimonio real nazarí. 2 El heredamiento de Daralgazi. 3 La ubicación de Daralgazi. 4 Una posible almunia nazarí. 5 Conclusión. 6 Apéndice documental. 7 Referencias bibliográficas.

\section{INTRODUCCIÓN}

La Guerra de Granada y la final conquista del emirato en 1492 propiciaron grandes transformaciones, tanto a nivel socioeconómico como político, para el territorio y la población de lo que había sido el reino nazarí. Más allá del evidente cambio del poder central, que pasa a la corona castellana, se observa una alteración veloz en las élites locales y rurales ${ }^{2}$. Sin duda, y como han demostrado autores como Enrique Soria o García Pedraza, hubo parte de la aristocracia nazarí que se integró de una manera o de otra en las nuevas redes de poder, como la familia de los Granada Venegas ${ }^{3}$ o los Cegríes ${ }^{4}$. No obstante, fueron muchos los castellanos que se aprovecharon de la favorable coyuntura para ocupar cargos y tierras a través de procesos de compraventa ligados a población musulmana que quería "pasar allende» o recibiendo mercedes de los Reyes Católicos. Muchos de ellos se beneficiaron a costa de los propios monarcas, como estudió en su momento Peinado Santaella ${ }^{5}$, y otros, como Sancho de Castilla, recibirían grandes propiedades como recompensa por sus leales servicios antes, durante y tras la guerra. Es muy conocida la concesión que hicieron a Sancho el Ayo del señorío de Gor ${ }^{6}$, pero hubo otros pagos en tierras no menos interesantes para esta familia. Analizaremos aquí la merced que recibió don Sancho el 3 de mayo de 1494 de la casa y heredamiento de Daralgazi ${ }^{7}$, perteneciente con anterioridad al patrimonio real nazarí, junto con otros

2 El cambio de élites nazaríes a castellanas en la Vega de Granada ha sido especialmente estudiado en Peinado Santaella, Rafael. «Un espacio aristocrático: propiedad y poblamiento en el sector occidental de la Vega de Granada a finales de la Edad Media». Fundamentos de Antropología, 1997, vol. 6-7, pp. 232-244.

3 Tenemos cuantiosa información sobre esta rama menor de la Casa real nazarí en trabajos como SoRIA MeSA, Enrique. «De la conquista a la asimilación. La integración de la aristocracia nazarí en la oligarquía granadina. Siglos XV-XVII». Áreas. Revista de Ciencias Sociales, 1992, vol. 14, pp. 49-64; o Soria Mesa, Enrique. «Entre reyes moros y oscuros labradores cristianos. Un itinerario familiar morisco: los Granada Venegas de Monachil (siglos xvi-XviII)». En Titos Martínez, Manuel (coord.). Monachil. Historia de un pueblo de la sierra. Monachil: Ayuntamiento de Monachil, 1995, pp. 159-182.

4 Destaca sobre este personaje el artículo de García Pedraza, Amalia. «La asimilación del morisco don Gonzalo Fernández el Zegrí: edición y análisis de su testamento». Al-Qantara: Revista de Estudios Árabes, 1995, vol. 16, pp. 41-58.

5 Véase Peinado Santaella, Rafael. «El patrimonio real nazarí y la exquisitez defraudatoria de los "principales" castellanos». Medievo Hispano: Estudios in memoriam del prof. Derek W. Lomax. Madrid: Sociedad Española de Estudios Medievales, 1995, pp. 297-318.

6 Sobre la alquería de Gor en el tránsito entre la Edad Media y Moderna hay dos trabajos clave, el primero de ellos más reciente: Soria Mesa, Enrique. «La venta de bienes de la casa real. El caso de Gor bajo Muhammad IX 'El Izquierdo'». Miscelánea de Estudios Árabes y Hebraicos, 1993-1994, vol. 42-43, n.o 1, pp. 291-304; y también Gómez LLORENTE, Manuel. «Los señoríos en el Reino de Granada: el señorío de Gor». Cuadernos de Estudios Medievales y Ciencias y Técnicas Historiográficas, 1985-1987, vol. XIV-XV, pp. 61-74.

7 AGS, CCA, CED, 1, 39, 2: Se trata de la copia de cedulario de un original desconocido cuya transcripción íntegra se encuentra en el Apéndice documental. 
documentos complementarios que aclararán algunos datos sobre una propiedad aún poco conocida.

El destinatario de la concesión pertenece a la Casa de Castilla, proveniente de una línea bastarda de Pedro I el Cruel. Sin embargo, resulta sumamente complejo saber si la merced es otorgada a Sancho el Ayo o a Sancho el Mozo. El primero es hijo del obispo Pedro de Palencia, del cual desconocemos la fecha exacta de nacimiento, así como los primeros años de su vida. Es posible que naciera entre los años treinta o cuarenta del siglo $\mathrm{XV}$, ya que muere alrededor de 1519, siendo conocido por su venerable edad más de dos décadas antes. Debió iniciar su carrera bajo la protección de Enrique IV, que lo pone a cargo de Palencia durante la guerra civil en 1464. Sin embargo, se sitúa a don Sancho en el bando del príncipe Alfonso durante el conflicto ${ }^{8}$, para posteriormente hacerse fiel, ya hasta su muerte, a la futura reina Isabel. Señor de Herrera de Valdecañas y corregidor de Palencia entre los años 1472 y $1474^{\circ}$, comenzará a convertirse en un personaje tan acaudalado como políticamente influyente en la región palentina.

Su prestigio y parentela con los reyes le lleva a obtener una situación privilegiada en la corte. El trato con los monarcas debió ser relativamente familiar, pues se habla de documentación expedida por Fernando e Isabel en la cual se llama "primo» a don Sancho $^{10}$. Asimismo, se convierte en consejero real y ayo del príncipe Juan tras la muerte de Johan Çapata, cargo por el que recibirá 200.000 maravedíes anuales ${ }^{11}$. Sus hijos mayores formarán parte de los caballeros más cercanos al heredero: Diego -sucesor de la casa nobiliar- se convertirá en caballerizo mayor y el joven Sancho será su maestresala. ${ }^{12} \mathrm{Si}$ confiamos en el Nobiliario de Alonso López de Haro, Sancho el Ayo participaría junto a sus dos hijos en conquistas tanto de territorio navarro como granadino ${ }^{13}$.

Es justo tras la toma de Granada cuando comienza la auténtica acumulación patrimonial de esta rama de la casa de Castilla, pues el ya citado señorío de Gor es entregado a Sancho el Ayo el 18 de marzo de $1494^{14}$; sin pasar siquiera dos meses, tiene lugar la merced de Daralgazi. Sancho el Mozo, que no era solo maestresala del príncipe Juan

8 Las Heras, Isabel; Fauve, María de y Forteza, Patricia de. «Consolidación de un linaje castellano en tiempos de los Reyes Católicos. El caso de Sancho el Ayo». En Siegrist, Nora y Zapico, Hilda (eds.). Familia, descendencia y patrimonio en España e Hispanoamérica, siglos XVI y XIX. 1. ${ }^{\mathrm{a}} \mathrm{ed}$. Mar del Plata: Editorial de la Universidad Nacional de Mar del Plata, 2010, p. 36.

9 Narganes Quijano, Faustino. "Acerca de los primeros corregidores en Palencia (ss. Xv-Xvi)». Publicaciones de la Institución Tello Téllez de Meneses, 1993, vol. 64, pp. 597-610.

10 Este mismo detalle es reiterado con vehemencia en el índice y memorial genealógico de Alonso Verdugo y Castilla para solicitar la grandeza de Espańa a finales del siglo xvıı. Grandeza que finalmente se obtiene hacia 1803. Véase: AHN, Sección Nobleza, Baena, C.2,D.113-114.

11 Esta elevada suma se ve acrecentada de forma común por otros pagos y mercedes. Francisco OLmos, Jose María. El príncipe heredero en las coronas de Castilla y Aragón durante la Baja Edad Media. Madrid: Universidad Complutense de Madrid, 2005, p. 584.

12 Fernández de Oviedo, Gonzalo. Libro de la Cámara Real del príncipe don Juan, oficios de su casa y servicio ordinario, ed. de Santiago Fabregat Barrios. València: Publicacions de la Universitat de València, 2006, p. 89.

13 Obra antigua, ofrece no obstante algunos detalles de interés sobre el personaje. López DE HARO, Alonso. Nobiliario genealógico de los Reyes y títulos de España. Madrid: Luis Sánchez, impresor real, 1622, p. 263.

14 AGS, RGS, leg., 149403, 3 
EL HEREDAMIENTO DE DARALGAZI: UNA PROPIEDAD ARISTOCRÁTICA EN LA VEGA DE GRANADA 152 SANDRA SUÁREZ GARCÍA

sino también capitán, recibe la taha de Boloduy por la defensa de la fortaleza de Salsas en 1504, así como los lugares de Belembín, Santa Cruz, Rochuelos y Nieles, aparte del título de capitán general de Rosellón y Cerdaña ${ }^{15}$, sin obviar los beneficios que recibía la familia de los bienes ubicados en su señorío de Herrera, que el Ayo convertirá en mayorazgo a favor de su hijo Diego.

En cuanto a Sancho el Mozo, podemos recordar que se le conoce por su participación en el sitio de Baza, donde resultó herido durante una escaramuza en $1489^{16}$. Sus cargos nos hacen pensar que la merced va dirigida a él y no a su padre, puesto que no se llama al recibidor de la heredad «señor de Gor», ni «señor de Herrera de Valdecañas» y tampoco «ayo», como en muchas ocasiones se presenta a su padre en otro tipo de documentos. De hecho, en todos los escritos que aluden a Daralgazi entre 1494 y 1495 solamente se cita a don Sancho como capitán y maestresala. Esta confusión entre padre e hijo excede estas líneas, ya que otros autores han atribuido la merced de Daralgazi a Sancho el Ayo, como Gómez Lorente o Garzón Pareja ${ }^{17}$. En todo caso, al sobrevivir el Ayo a Sancho el Mozo -que no tuvo descendencia- todos los bienes irían a parar primero al padre, para pasar después a manos de su hermano, don Diego. Se trata, en suma, de un linaje encabezado por Sancho el Ayo, que formará parte de una élite castellana con una notoria influencia sobre el territorio recién conquistado ${ }^{18}$.

\section{ACERCA DEL PATRIMONio REAL NAZARí}

Aunque durante las últimas décadas se hayan hecho avances respecto al conocimiento de las características del rico patrimonio del estado nazarí y su Hacienda, aún resulta complejo definir con exactitud su valor, tamaño o las particularidades de su administración. Seguimos partiendo de planteamientos como el de Isabel Álvarez de Cienfuegos ${ }^{19}$, Miguel Ángel Ladero Quesada ${ }^{20}$ o Emilio Molina, quien apuntó a la división del patrimonio andalusí, no siempre clara, en tres entidades principales: el mustajlas, el

15 Matarín Guil, Manuel Francisco. «Los Castilla, señores jurisdiccionales de la taha de Boloduy». En Andújar Castillo, Francisco y Díaz López, Pablo (coords.). Los señoríos en la Andalucía Moderna. El Marquesado de los Vélez. Almería: Instituto de Estudios Almerienses, 2007, p. 510.

16 Pulgar, Hernando del. Crónica de los señores Reyes Católicos Don Fernando y Doña Isabel de Castilla y de Aragón. Valencia: Imprenta de Benito Monfort, 1780, p. 352.

17 Gómez Lorente, «Los señoríos en el Reino de Granada», p. 67 y Garzón Pareja, Manuel. «Señoríos del reino de Granada». Boletín de la Real Academia de la Historia, vol. CLXXIV, 1977, p. 588.

18 No obstante, la Casa de Castilla no gozó del mismo poder e influencia en Granada que otras estirpes nobiliarias como los Tendilla, Fernández de Córdoba o la Casa de Arcos, cuya relevancia bien recoge Soria Mesa, Enrique. Señores y oligarcas: los señorios del Reino de Granada en la Edad Moderna. Granada: Universidad de Granada, 1997, p. 52.

19 Cabe citar su análisis, ya clásico: Álvarez de Cienfuegos, Isabel. «La Hacienda de los nasríes granadinos». Miscelánea de Estudios Árabes y Hebraicos, 1959, vol. VIII, pp. 99-144.

20 Recordamos un corto pero relevante estudio en LAdero Quesada, Miguel Ángel. «El duro fisco de los emires». Dos temas de la Granada nazari, Cuadernos de Historia, anexo de Hispania, 1969, vol. 3, pp. 320-346. 
Bayt al-māl y los legados píos o habices ${ }^{21}$. El primero corresponde a los bienes privados o personales del monarca, mientras el Bayt al-mäl se puede entender como el "erario público», respondiendo a los bienes del estado. Estos dos «tesoros» se ven afectados por trasvases o intercambios según convenga a las circunstancias socioeconómicas y políticas, lo cual se puede apreciar muy bien durante el ocaso del reino nazarí ${ }^{22}$. Hablamos de entidades que recogen no solo rentas e impuestos sino una gran cantidad de bienes raíces. Especialmente dentro del mustajlas encontramos un elevado número de casas, palacios, almunias, huertas y, con toda probabilidad, también hornos, molinos y tiendas de tipología diversa ${ }^{23}$.

No es nuestra intención profundizar en tal cuestión, mas debemos tener en cuenta que muchas de estas propiedades fueron cedidas por el monarca a otros miembros de la familia real, especialmente a figuras femeninas, configurando lo que posteriormente se conocerá como las propiedades de las «reinas moras», término excesivamente genérico para una realidad más compleja. Algunos ejemplos destacados de la diversidad de su patrimonio lo encontramos en las salinas de Motril, que pertenecían a Çeti Fátima y su madre, que las recibieron probablemente de Muhammad IX el Izquierdo ${ }^{24}$, o el Corral del Carbón de Granada ${ }^{25}$. Los hijos de los reyes nazaríes fueron otros beneficiarios de dádivas, como se aprecia en el curioso caso de Soraya, la segunda esposa de Abū-1-Hasan 'Alî, y sus hijos, los infantes de Granada ${ }^{26}$. De forma paralela, como recoge Santaella, el patrimonio real de los nazaríes disminuyó a medida que avanzaba la guerra, pues había una necesidad evidente de financiar la defensa y asegurar lealtades ${ }^{27}$.

A pesar de estas pérdidas, el patrimonio privado de la familia real nazarí sigue siendo considerable a finales del siglo xv, como se puede comprobar en las negociaciones que se emprenden tras la derrota de Boabdil. Hernando de Zafra, secretario de los Reyes

21 Molina López, Emilio. "El mustajlas andalusí (I) (s. VIII-XI)». Revista del Centro de Estudios Históricos de Granada y su Reino, 1999-2000, vol. 13-14, pp. 99-189.

22 Molina López, Emilio y Jiménez Mata, María del Carmen. «La propiedad de la tierra en la Vega de Granada a finales del siglo xv. El caso de Alitaje». Anaquel de Estudios Árabes, 2001, vol. 12, pp. 453-454.

23 El tema de los hornos es tratado de forma especialmente interesante en Trillo SAN José, Carmen. "Hornos de pan en la ciudad de Granada: precedentes nazaríes y transformaciones castellanas». En Marín López, Rafael (ed.). Homenaje al Profesor Dr. D. José Ignacio Fernández de Viana Vieites. Granada: Universidad de Granada, 2012, pp. 615-629.

24 Malpica Cuello, Antonio. «Las salinas de Motril. Aportación al estudio de la economía salinera del Reino de Granada a raíz de su conquista». Baetica. Estudios de Arte, Geografía e Historia, 1981, vol. 4, p. 151.

25 Torres Balbás, Leopoldo. «Las alhóndigas hispanomusulmanas y el Corral del Carbón de Granada». Al-Andalus, 1946, vol. XI, p. 235.

26 Los bienes que recibieron dieron lugar a una serie de probanzas que han sido fundamentalmente estudiadas en: López de Coca Castañer, José Enrique. «Granada en el siglo xv: Las postrimerías nazaríes a la luz de la probanza de los infantes don Fernando y don Juan». En Cabrera Muñoz, Emilio (coord.). Andalucía entre Oriente y Occidente (1236-1492). Actas del V Coloquio Internacional de Historia Medieval de Andalucía. Córdoba: Diputación de Córdoba, 1988, pp. 599-641; MalpiCa Cuello, Antonio y Trillo SAN José, Carmen. «Los infantes de Granada. Documentos árabes romanceados». Revista del Centro de Estudios Históricos de Granada y su Reino, 1992, vol. 6, pp. 361-375.

27 Peinado Santaella, «El patrimonio real nazarí y la exquisitez defraudatoria», pp. 299-300; y TRILlo SAN José, Carmen. "El Nublo, una propiedad de los infantes de Granada». En Homenaje al profesor José María Fórneas Besteiro. Granada: Universidad de Granada, 1995, vol. 2, pp. 867-879. 
EL HEREDAMIENTO DE DARALGAZI: UNA PROPIEDAD ARISTOCRÁTICA EN LA VEGA DE GRANADA

SANDRA SUÁREZ GARCÍA

\section{4}

Católicos y auténtico artífice de las capitulaciones de Granada -en palabras de Ladero Quesada-, concertará pactos, compras y entregas gratuitas de bienes inmuebles entre los monarcas vencidos y vencedores ${ }^{28}$. El último rey nazarí solicitará a don Fernando y dońa Isabel, como merced personal, «que todos los heredamientos del Rey de Granada y de las señoras Reynas, y de los alcaydes, de tierras é de herencias y casas y otras cosas, sean francos de todos los derechos agora y después de agora para siempre, todo el tiempo que estouieren en su poder y de sus hijos; y que los vendan en qualquier tiempo que los quisieren vender y a quien quizieren ${ }^{29}$. Esta petición será atendida, al menos en parte, al permitir a Boabdil y a su familia la libre venta de bienes con la condición de que los monarcas fueran requeridos para la compra en primer lugar ${ }^{30}$.

Algunos documentos que aluden al traspaso de los bienes de las reinas moras a las arcas castellanas fueron publicados a mediados del siglo $\mathrm{XIX}^{31} \mathrm{y}$ estudiados a comienzos del xx por Gaspar Remiro en su clásico escrito Partida de Boabdil allende con su familia $y$ principales servidores ${ }^{32}$. Entre estas páginas encontramos una sucinta enumeración de propiedades que pasaron a los monarcas castellanos de forma gratuita, donde cabe mencionar el Alcázar Genil y Dar al-Bayda, pero entre las cuales se cita también Daralgazi:

«Y lo que queda para vuestras Altezas sin costa ninguna son las huertas de Genin Aljof, y Genin Cidi Mocliz, y Genin Cidi Hamet que tiene Hinestrosa, y Genin Alcadí, y Genin Alfares, é las partes del alcazar Xenil que tiene el Gallego, y Genin Alcadí que tiene Gonzalo Fernandez, y Dar-al-bayda que tiene el corregidor [...] y Dar-algazi que es una muy buena heredad y la mejor que ha en toda la vega ${ }^{33}$.

\section{El heredamiento de Daralgazi}

La primera noticia que tenemos sobre Daralgazi nos llega a través de Lisan al-Din Ibn al-Jatib, en su conocida al-Ihạț fî̀ tārīj Garnāța, una de las fuentes más relevantes para el estudio del reino granadino durante el siglo xiv. Recoge el topónimo qaryat dār-al-gāzzīí

28 Ladero Quesada, Miguel Ángel. Hernando de Zafra, secretario de los Reyes Católicos. Madrid: Dykinson, 2005, p. 28.

29 Garrido Atienza, Miguel. Las capitulaciones para la entrega de Granada. Granada: Paulino Ventura Traveset, 1910, p. 241.

30 Esta estipulación fue pasada por alto en numerosas ocasiones, especialmente por parte de los nobles castellanos, quienes compraron gran número de propiedades de las reinas moras, como ha estudiado Santaella en su trabajo, ya citado, «El patrimonio real nazarí y la exquisitez defraudatoria».

31 Salvá, Miguel y Sainz de Baranda, Pedro. Colección de documentos inéditos para la Historia de España. Tomo XI. Madrid: Imprenta de la viuda de Calera, 1847, pp. 543-548.

32 Gaspar Remiro, Mariano. «Partida de Boabdil allende con su familia y principales servidores». Revista del Centro de Estudios Históricos de Granada y su Reino, 1912, vol. 2, pp. 57-111.

33 Salvá y Sainz de Baranda, Colección de documentos inéditos, pp. 543-544.

34 "Alquería Casería de Gāzī o del Conquistador», según Jiménez Mata, aunque ella vincule el topónimo a un caserío llamado Gazi en el término de Peligros que no corresponde a nuestro Daralgazi. JimÉnEz Mata, María del Carmen. La Granada islámica. Contribución a su estudio geográfico-político-administrativo a través de la toponimia. Granada: Universidad de Granda, 1987, p. 386. 
sin aludir en ningún momento a su ubicación ${ }^{35}$. Un siglo después se cita, como ya hemos visto, en la relación de bienes que Hernando de Zafra recoge para los Reyes Católicos, por parte de las «reinas moras», describiendo su carácter de gran heredad de la Vega, sin preocuparse en demasía por revelar datos sobre su emplazamiento. Poco después, hacia 1494 cuando ya tuvo lugar la marcha de la familia real nazarí a Fez, conocemos al menos cuatro documentos que hacen alusión a Daralgazi.

Todos ellos se encuentran directamente relacionados con la cesión del heredamiento a Sancho de Castilla, siendo el más antiguo de los mismos la propia merced, fechada como vimos a 3 de mayo de 1494. Aquí, como apuntamos, don Sancho es presentado como capitán y maestresala del príncipe Juan, digno de recibir tal propiedad por sus méritos diarios en el servicio a los monarcas y especialmente por su participación en la Guerra de Granada. Tras alabar su persona, comienza la alusión detallada al bien que se entrega:

«Vos fasemos graçia e merçed e donaçión pura e perfeta e acabada que es dicha entre biuos no reuocable, para agora e para syempre jamás, para vos e para vuestros ferederos e suçesores e para aquel o aquellos que de vos o dellos ouyeren causa o razón, en qualquier manera, de nuestro feredamyento e casa de Daralgazi, que es en térmyno e juridiçión de la nuestra çibdad de Granada lo qual nos ouymos de la reyna mora, madre del rey Muley Baudil nuestro vasallo, al tiempo quel dicho Rey e ella se fueron de nuestros reynos e se pasaron allende con todos sus térmynos e tierras destritos e terretorios que ella ay e ouiere de aquí adelante, e con las casas, huertas, corrales, viñas e tierras labradas e non labradas que son nuestras e nos pertenesçen en el dicho heredamyento y en sus térmynos e tierras. E con los prados e pastos, exidos, abreuaderos e sotos e árboles frutuosos e ynfrutuosos e montes e dehesas, ríos e molinos e fuentes e aguas corrientes, estantes e manantes e otras qualesquier cosas que a nos pertenesçen e pertenesçer pueden e deuen en qualquier manera en el dicho heredamyento e casas de Daralgasi e sus térmynos por rasón del señorío e propiedad dél por virtud de la dicha conpra, eçebto la juridiçión, que esta quede para la çibdad de Granada» ${ }^{36}$.

Este fragmento resulta de gran interés al respaldar una vez más el origen real de la heredad, pues cita no solo la figura de Boabdil sino también la de su madre. Por añadidura, se enumeran algunos de los elementos físicos que componen Daralgazi. La imagen que transmite es la de un heredamiento dedicado a la explotación agrícola con una casa principal y probablemente algunas construcciones complementarias como casas de menor entidad y corrales. Estos edificios tuvieron que estar ocupados en el momento de la cesión, ya que en el segundo folio de la misma merced se habla de un «tenedor» y «los caseros e renteros del dicho heredamiento e casa de Daralgasi». No puede tampoco pasar desapercibida la alusión a elementos hidrográficos como fuentes y ríos, u otros detalles como molinos, pastos, dehesas y abrevaderos. Estos últimos aspectos incitan a pensar que, o bien se trata de una fórmula genérica, o Daralgazi integraba toda una serie de

35 Ibn aL-Jatib. al-Ihāṭa fì tārīj Garnāta. Tomo 2. Inan, 'Abd Allah (ed.). El Cairo, 1955, p. 136, citado en: García Pulido, Luis José. «Sobre el emplazamiento de los restos arqueológicos de la Casa de las Gallinas». Al-Qantara: Revista de Estudios Árabes, 2007, vol. 28, n. ํ 1, p. 233.

36 AGS, CCA, CED, 1, 39, 2: 1. 
EL HEREDAMIENTO DE DARALGAZI: UNA PROPIEDAD ARISTOCRÁTICA EN LA VEGA DE GRANADA

SANDRA SUÁREZ GARCÍA

\section{6}

elementos óptimos tanto para la práctica agraria como ganadera. Se trataría de una visión lucrativa de la propiedad que encajaría con la descripción que da de ella Hernando de Zafra. Al avanzar en el documento, se explica asimismo que la jurisdicción de Daralgazi permanece en manos de la ciudad de Granada, dato de valor, puesto que no se constituye en señorío como sí ocurría con Gor, aunque se le llega a denominar como tal. Esta cuestión puede vincularse con el posible interés que tuvieron los Reyes Católicos de dotar a Granada de un alfoz significativo, sin intromisión señorial, idea que ya ha sido abordada en la historiografía granadina.

Poco después, el 22 de mayo de 1494, los reyes comienzan a solicitar a Granada información sobre las rentas que producía el heredamiento de Daralgazi, tanto en el pasado como las que puede dar a partir de ese momento ${ }^{37}$. La demanda parece no haberse cumplido, pues, tras casi tres meses, el 9 de agosto se reitera la petición de averiguar cuánto rentaba y puede rentar Daralgazi por año a Andrés Calderón, corregidor de Granada ${ }^{38}$. Esta insistencia en conocer el valor de la renta anual de la posesión se explica a través de dos documentos posteriores, ambos fechados el 18 de marzo de 1498. Don Fernando y dońa Isabel solicitan a fray Hernando de Talavera, primer arzobispo de Granada, que busque entre las posesiones de los monarcas en Granada una que rente 20 mil maravedíes. Esta suma es crucial para llegar a los 60 mil maravedíes anuales prometidos a don Sancho de Castilla en juro de heredad, ya que se «averiguó que [Daralgazi] vale de renta en cada un año quarenta myll maravedíes poco más o menos» ${ }^{39}$.

Conocer el valor aproximado de la producción anual del heredamiento es uno de los datos más valiosos que podemos obtener, a falta de su extensión y un registro detallado de los cultivos. Cabe tener mucho cuidado al reflexionar sobre precios, costes e importes en la Granada entre siglos, pues hay notorios cambios sobre todo en lo referente al valor de la tierra. Jiménez Mata y Emilio Molina observaron un descenso en el precio de las tierras durante finales del siglo XV y un paulatino aumento a comienzos del XVI a raíz de la conquista ${ }^{40}$, pero se trata de una cuestión que aún debe estudiarse con mayor profundidad. Optaremos en este caso por comparar este valor estimado entre 1494 y 1495 con la renta anual de una propiedad que creemos semejante en tipología y cercana a nivel geográfico, como es Darabenaz.

\section{La ubicación de Daralgazi}

En un estudio reciente, García Pulido trató la polémica vinculación de Daralgazi con lo que debería ser hoy la Casa de las Gallinas o dầr al-Wādì, a raíz de una casi certera equivocación documental durante el siglo xvi. Este autor llegó a situar con precisión los restos de esta casa palaciega nazarí entre el barranco de Casa de las Gallinas y el barranco de Casilla, mientras vinculó, a través de textos de habices y aguas, el pago de Daralgazi con el Zaidín y Darabenaz, probablemente situado en algún camino hacia Huétor

37 AGS, CCA, CED, 1, 43, 1.

38 AGS, CCA, CED, 1, 90, 1.

39 AGS, RGS, leg., 149503, 15; y AGS, CCA, CED, 2, 2-1, 51, 2.

40 Molina López y Jiménez Mata, «La propiedad de la tierra en la Vega de Granada», p. 459. 
$\mathrm{Vega}^{41}$. Tras observar con mayor detenimiento los fragmentos de los habices recogidos por Hernández Benito por un lado, y los de Villanueva Rico por otro, esta propuesta parece lógica y probable. Podemos apuntar a la claridad de dos entradas de los habices de 1503 y 1527, respectivamente:

«Otra haça en Çaydin, tienela Juan el Lavbili vezino a gima Naranja en XII ps. cada anno, quedale DIII DIIII DV annos de su arrendamiento, es de VI marjales el haça alinde de Dar Algazi e de Torme e del Balat $»^{42}$.

«Visitose una haza de dos marjales que está Junto con la alquería de Güetor, como salen de dicha alquería para ir a daralgazi, a mano derecha, era dicha haza de la Iglesia de San Joseph, corría por arrendamiento, lindava por tres partes con tres caminos» ${ }^{43}$.

Queremos apuntar también, aunque sea brevemente, que en un reciente estudio sobre la alquería de La Zubia a través de los libros de habices de 1503 y 1505, hemos podido apreciar que una de las familias de mayor notoriedad de la región llevaba el nombre de Gasi/Gazi//Algazi. Los miembros de este linaje residieron en la zona sur de Granada, dispersos entre las alquerías de La Zubia, Monachil y Los Ogíjares, muy cercanos, por lo tanto, a la posible ubicación de Daralgazi, por lo que creemos que pudo existir una relación entre el heredamiento antiguo y esta familia, quizás incluso estuvieran vinculados a nivel patrimonial antes de pasar a la familia real nazarí, aunque desde luego se trata solo de una suposición ${ }^{44}$.

También en el Archivo Municipal de Granada, en el Juzgado de Aguas, se pueden encontrar pleitos y demandas entre regadores del Zaidín y de Daralgazi, así como pleitos con Diego de Castilla, hijo de Sancho el Ayo, que confirman la cercanía de Daralgazi a estos pagos del cinturón meridional de la actual Granada ${ }^{45}$. Es más, recientemente se publicó una transcripción del Libro del apeo y deslinde del pago del Zaidín y Daralgazi ${ }^{46}$ del año 1572 . Este documento debe ser la última evidencia necesaria para afirmar que el pago de Daralgazi estaba anexo al Zaidín, siendo en algunos puntos limítrofe a Huétor Vega.

Especialmente interesante resulta descubrir las dimensiones y cultivos de un pago amplio: más de 20 marjales de hazas calmas; otros 11 marjales dedicados al cultivo del

41 Pulido comenta además algunos aspectos relacionados con la etimología del topónimo, cuestión en la que no entraremos. García Pulido, «Sobre el emplazamiento de los restos arqueológicos», pp. 234-235.

42 Hernández Benito, Pedro. La Vega de Granada a fines de la Edad Media según las rentas de los habices. Granada: Diputación Provincial de Granada, 1990, p. 128, entrada 162.

43 Villanueva Rico, María del Carmen. Casas, mezquitas y tiendas de los habices de las iglesias de Granada. Madrid: Instituto Hispano-Árabe de Cultura, 1966, p. 88, entrada 237.

44 Suárez García, Sandra. «Los habices de la Vega de Granada como forma de conocimiento del reino nazarí y su transformación tras la conquista: La alquería de La Zubia». Espacio, Tiempo y Forma. Serie III, Historia Medieval, 2018, vol. 31, pp. 641-667.

45 Pulido cita varios documentos que se pueden tener en consideración, como el leg. 3455, 33: «Querella presentada por Blas Hernández, regador en el pago del Zaydín, contra Juan Pérez, labrador en el pago de Daralgazi...». Véase: García Pulido, «Sobre el emplazamiento de los restos arqueológicos», p. 234.

46 Padilla Mellado, Lorenzo. Libro del apeo y deslinde del pago del Zaidin y Daralgazi. Año de 1572 (Traslado del original). Granada: Universidad de Granada, 2017. 
EL HEREDAMIENTO DE DARALGAZI: UNA PROPIEDAD ARISTOCRÁTICA EN LA VEGA DE GRANADA SANDRA SUÁREZ GARCÍA

\section{8}

trigo; casi 65 marjales de huerta; y otras dos hazas que suman 18 marjales, con más de 30 olivos $^{47}$. Tenemos constancia de unos 114 marjales, aproximadamente, pertenecientes solo a aquellos moriscos expulsados cuyos bienes quedaban libres para el apeo, sin contar ni la propiedad de cristianos y mucho menos el heredamiento que en este momento ya pertenece a Sancho de Castilla, hijo de Diego y por lo tanto nieto del Ayo.

Este documento, aun no ofreciéndonos datos mayores sobre las características de la propiedad, nos revela muchos de los linderos del heredamiento de los Castilla, a pesar de su fecha tardía. Así, linda con las hazas calmas y de trigo de los Tarifes, huertas de habices de García de Baeza, morisco vecino de Granada, y la huerta de Hamama, de la misma población. Junto a estas hazas de Daralgazi, también se citan linderos del pago del Zaidín con don Sancho, como el olivar de un morisco llamado Malaquí, u otro de Benaxixa ${ }^{48}$. Uno de los linderos más interesantes es aquel que se denomina como «huerta de la Ynquisiçión»

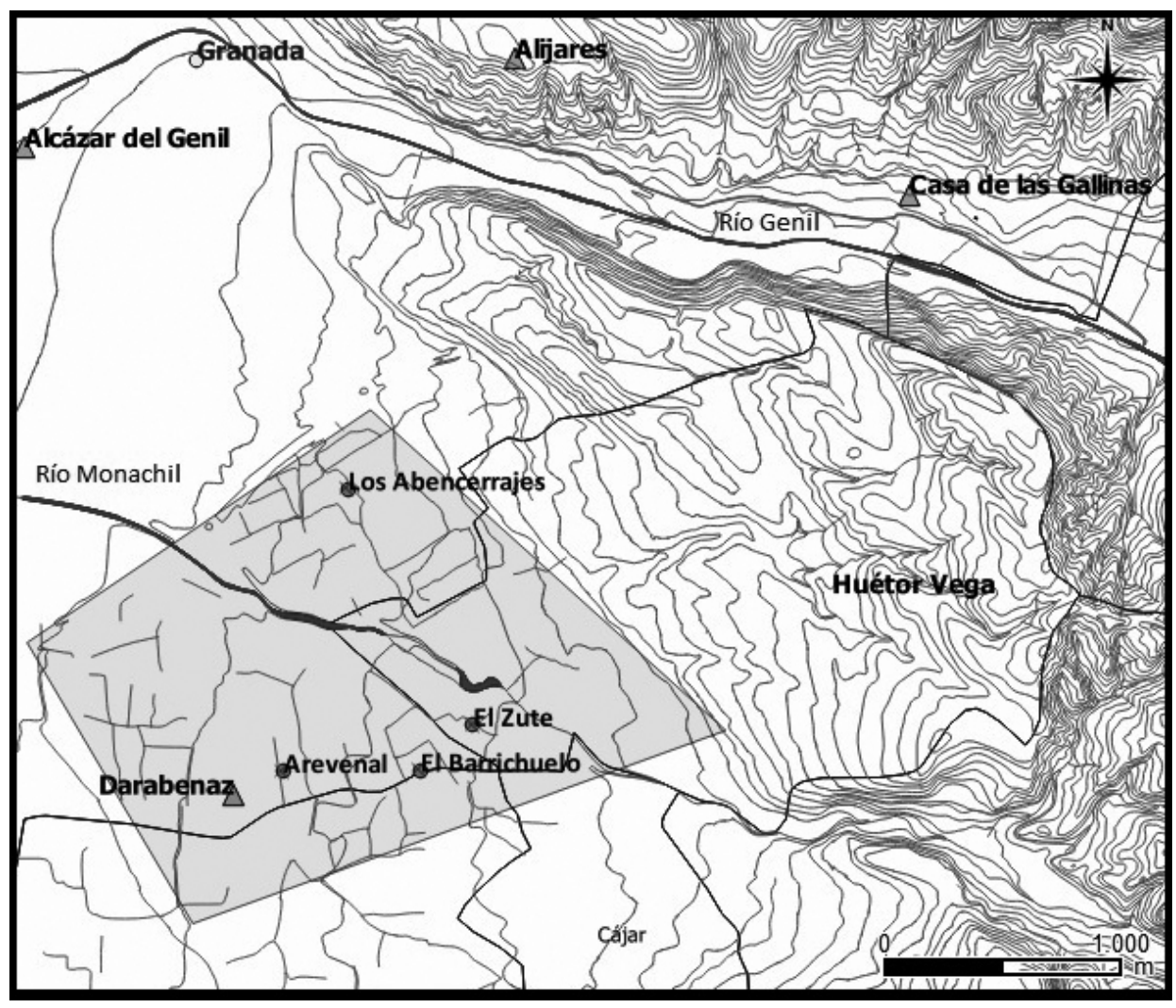

Mapa 1. Posible ubicación de Daralgazi en relación con algunos pagos y almunias conocidas.

47 Cálculos basados en fragmentos del apeo dedicados a Daralgazi: Ibidem, pp. 93-94 y 97-99.

48 Ibidem, pp. 40 y 57. 
junto a otras propiedades cercanas del Santo Oficio, ya que hoy en día se conserva un Cortijo de la Inquisición a muy poca distancia de Darabenaz. Además, nos encontramos numerosos lindes en los que se hace referencia a una acequia principal y el camino a Huétor.

Toda esta información nos hace pensar que Daralgazi pudo encontrarse o bien en el mismo pago que Darabenaz, llamado hoy del Arevenal, densamente poblado de cortijos, o en otros muy cercanos a este, como El Zute, El Barrichuelo o Los Abencerrajes. Existe también una elevada posibilidad de que se encontrara en lo que hoy es el Zaidín urbanizado. Sin embargo, hay una necesidad imperiosa de conocer mejor este territorio a través de la prospección sistemática para encontrar e interpretar posibles restos, cuestión compleja en aquellas tierras que hoy se integran en el entramado urbano. Recientemente se publicaron algunos avances de excavación, en los que se habla de estructuras civiles y religiosas de período nazarí en el entorno de Darabenaz, especialmente en el yacimiento del Cobertizo Viejo ${ }^{49}$. No podemos descartar que alguna de estas edificaciones u otros restos materiales cercanos puedan corresponder con parte del heredamiento de Daralgazi, tema sobre el que volveremos en breves páginas. Consideramos muy poco probable, en cambio, la posibilidad de que el heredamiento de Daralgazi concuerde con el Cortijo de Gazi en el entorno del Soto de Roma que cita Martínez Vázquez ${ }^{50}$, aunque en dicho lugar pudiera existir una toponimia semejante.

\section{UNA POSIBLE ALMUNIA NAZARÍ}

Llegados a este punto, es necesario preguntarse sobre la naturaleza de nuestro objeto de análisis: ¿qué era realmente Daralgazi? Vimos que Ibn al-Jatib la citaba como qarya, mientras a través de la merced a don Sancho transmite la imagen de una gran explotación agropecuaria. Ante nuestra interpretación, existe una gran probabilidad de que Daralgazi constituyera una almunia, y no solamente por el componente dār en su nombre, tan común en construcciones de este tipo ${ }^{51}$. El término al-munya responde a toda una serie de conceptos diversos entre sí, aunque la acepción más válida para nuestro estudio es la de finca de recreo, propiedad de la aristocracia andalusí que sirve como centro de explotación agraria, situado de forma general entre el mundo rural y el urbano. Comúnmente se componen de una casa principal rodeada de huertas, aguas y jardines. Hay numerosas noticias sobre su uso en la Córdoba califal, como punto de reunión política, lugar de descanso y ocio para los emires, así como fuente de importantes recursos económicos ${ }^{52}$.

49 González Martín, Carlos; Buendía Moreno, Antonio y Aznar Pérez, Juan Carlos. «Darabenaz, una alquería compleja. Avance de los resultados de las intervenciones arqueológicas». Estudios sobre Patrimonio, Cultura y Ciencias Medievales, 2015, vol. 17, pp. 161-180.

50 Martínez Vázquez, Luis. La Vega de Granada. Transformación y cambio de los paisajes entre el Reino Nazari y el Reino de Granada. Granada: Universidad de Granada, 2015, pp. 375-376.

${ }_{51}$ Dā $r$ significa morada o casa, y fue empleado con asiduidad para construcciones palaciegas en todo al-Andalus. En Granada se aplica también a almunias, cortijos y explotaciones agrícolas. Véase: JuEz JARros, Francisco. Simbolos de poder en la arquitectura de al-Andalus. Tomo 1. Madrid: Universidad Complutense de Madrid, 1999, p. 224.

52 Trillo SAN José, Carmen. «Les munya-s et le patrimoine royal à l'epoque nasride (XIII ${ }^{\mathrm{e}}-\mathrm{XV}^{\mathrm{e}}$ siècles). Entre le souverain et les élites». Annales Islamologiques, 2014, vol. 48, n. ${ }^{2}$, p. 173. 
Recientemente, se ha reactivado el estudio sobre las almunias granadinas gracias a los esfuerzos de autores como Carmen Trillo o Navarro Palazón ${ }^{53}$. La persistencia de almunias en la capital nazarí es evidente, pues nos son bien conocidas algunas de propiedad real como el Generalife o el Alcázar Genil. Más dificultoso resulta conocer aquellas menos fastuosas y no orientadas específicamente a la ostentación del poder, cuyas construcciones no se han analizado con suficiente profundidad hasta el momento, pues se desconoce en buena medida la ubicación de sus restos. Con todo, el paisaje de la Vega de Granada estaba impregnado por un gran número de almunias, tal como lo describe Ibn al-Jatib en un texto tan imprescindible como conocido:

«En la parte norte de la llanura hay unas almunias de tan gran valor y elevada calidad que para pagar su precio serían menester fortunas de reyes. Algunas de ellas hay que rentan al año medio millar de dinares de oro, a pesar del escaso coste de las verduras en esta ciudad. Unas treinta de estas almunias pertenecen al patrimonio privado del sultán. Las cińen y se unen con sus extremos unas magníficas fincas nunca esquilmadas, siempre fecundas, cuyas rentas alcanzan en nuestro tiempo los 25 dinares de oro. Por cierto, que la hacienda pública es inferior a la riqueza de algunas de estas fincas pertenecientes al patrimonio del sultán. Todas ellas tienen casas magníficas, torres elevadas, eras amplias, palomares y gallineros bien acondicionados y más de veinte se encuentran dentro del área de la ciudad y del recinto de su muralla ${ }^{54}$.

Si aceptamos la ubicación propuesta para Daralgazi, debemos tener en cuenta que estamos en una zona geográfica de concentración de almunias, tales como la citada Darabenaz, Daracohayle, Dar Nublo o Dar Adefla, como ha estudiado Carmen Trillo ${ }^{55}$. Tuvimos la oportunidad de encontrar, muy recientemente, un primer indicio de la ubicación de Daracohayle, localizando un pago en la cartografía parcelaria denominado «Arco Jaire». Una vez más, se ubica a una breve distancia de Darabenaz, en término de La $\mathrm{Zubia}^{56}$. Cumple asimismo con alguno de los criterios que encontramos en almunias mejor conocidas: perteneció a la familia real granadina; presenta rasgos de gran explotación con una aparente finalidad económica e incluye en su término una casa principal y otros edificios anejos (casas, corrales, molinos), con una probable relación de subordinación. En la merced otorgada a don Sancho se habla no solo de huertas y viñas, sino también de árboles, tierras labradas y no labradas y otros elementos, que ofrecen esa visión ecléctica pero intrincada -respecto a cultivos y aprovechamiento de la tierra- de los complejos agrarios dependientes de una almunia. Trillo apunta también a que la explotación agraria de la almunia se delegaba en administradores, conocidos más tarde como mayordomos

53 Debemos destacar la obra anteriormente citada, así como los trabajos que saldrán en TriLlo SAN José, Carmen y Navarro Palazón, Julio (eds.). Almunias del Occidente islámico: solaz y producción. Granada: Universidad de Granada (en prensa).

54 Iвn al Jатів. Historia de los Reyes de la Alhambra: el resplandor de la luna llena acerca de la dinastía nazari (Al-Lamha al-badriyya fi l-dawlat al nastiyya). Trad. de Emilio Molina López y María Casciaro Ramírez. Granada: Universidad de Granada, 2010, pp. 104-105.

55 Trillo SAN José, "Les munya-s», p. 185.

56 SuÁrez García, «Los habices de la Vega de Granada». 
en algunos documentos castellanos ${ }^{57}$. ¿Podríamos ver al «tenedor» de Daralgazi, en el momento anterior a su cesión a don Sancho, como un posible administrador de la misma? Es evidente que los monarcas nazaríes y las «reinas moras» no podían hacerse cargo directo de todos sus bienes.

Más allá de los linderos, hay un detalle del apeo anteriormente citado, que no puede pasar desapercibido, y es que en varias de sus entradas se hace referencia a las «piedras» o "paredes de Daralgazi» como en los siguientes fragmentos: «Y ansymysmo alinda con la hazienda de don Sancho de Castillla, la qual dicha haçienda alinda con las paredes de Daralgazi ${ }^{58} \mathrm{y}$ "Consta por el repartimiento pasar la linde del arrendamiento hasta el tomadero de las piedras de Daralgazi ${ }^{59}$. ¿Cabe la posibilidad de que en 1572 solo quedaran restos de una construcción mayor que recibía este mismo nombre? ¿Puede acaso referirse a lo que podemos considerar una almunia en ruinas? También existe la alternativa de que se trate de cercas agrarias o puntos de referencia del apeo, lo cual no podemos descartar.

Hemos aludido con anterioridad a las excavaciones que tuvieron lugar en el Cobertizo Viejo, muy cerca de Darabenaz. García Porras apunta a que hubo dos hipótesis de partida para conocer la funcionalidad del espacio excavado, que parten ambas del siglo XIX: o bien se encontraban ante una posible almunia, como describían los hermanos Oliver, o ante una construcción religiosa, como proponía Almagro Cárdenas ${ }^{60}$. Frente a un comentario de tal interés, nos acercamos al escrito de los Oliver. Citan el Cobertizo Viejo por su nombre, vinculándolo a un fragmento del famoso Viaje a España de Andrea Navagero, que conoció Granada en 1526. El italiano habla de forma distendida sobre las ruinas que quedan de las antiguas almunias de Los Alixares, Dar al-Arusa y la Casa de las Gallinas, para hacer una breve referencia a un palacio que se encuentra en un mejor estado de conservación ${ }^{61}$. Curiosamente, los Oliver ligan este palacio al Cobertizo Viejo: Navagero lo ubica en la «Huerta de la Reina», que en razonamiento de los Oliver debe tratarse de la «Huerta de Gor» ${ }^{62}$. Si su deducción fuera acertada, tendríamos un doble motivo para identificar el Cobertizo Viejo con Daralgazi, ya que no solo correspondería a la propiedad de una «reina», sino también aparecería la alusión a los duques de Gor, herederos de don Sancho el Ayo. No obstante, es posible que figurara como una de esas otras «casas moriscas» del pago del Aravenal que citan los Oliver ${ }^{63}$, ya que los análisis realizados por Porras y Álvarez reconocen la estructura encontrada como un morabito ${ }^{64}$.

57 Trillo SAN José, Carmen. «Fincas de recreo de la Granada nazarí, según las fuentes castellanas: El Nublo, La Alberzana y Cármenes de Aynadamar». En Trillo San José y Navarro Palazón (eds.), Almunias del Occidente islámico, p. 499.

58 Padilla Mellado, Libro del apeo y deslinde, p. 41.

59 Ibidem, p. 43.

60 Álvarez García, José Javier y García Porras, Alberto. "La zawiya del “cobertizo viejo” (Granada)». Anuario Arqueológico de Andalucía 2003, 2006, vol. 3, n.o 1, p. 429.

${ }_{61}$ FabiÉ, Antonio (trad. y ed.). Viajes por España de Jorge de Einghen, del Baron de Rosmithal de Blatna, de Francisco Guiccardini y de Andrés Navajero. Madrid: Librería de los bibliófilos, 1879, pp. 286-287.

62 Oliver Hurtado, José y Oliver Hurtado, Manuel. Granada y sus monumentos árabes. Málaga: Imprenta de M. Oliver Navarro, 1875, p. 371.

63 Ibidem.

64 Álvarez García y García Porras, «La zawiya del “cobertizo viejo”», pp. 435-436. 
EL HEREDAMIENTO DE DARALGAZI: UNA PROPIEDAD ARISTOCRÁTICA EN LA VEGA DE GRANADA 162 SANDRA SUÁREZ GARCÍA

La idea de que Daralgazi estuviera en ruinas a finales del siglo xvi, insinuada en el apeo, sufre cierta contradicción con un breve fragmento de texto que podemos encontrar en La toma de Granada y caballeros que concurrieron á ella, de Joaquín Durán y Lerchundi. Nos trae una noticia tan tardía como del año 1893, hablando de Sancho el Ayo y sus hijos:

"Además se conserva en la casa de los Duques de Gor, sus descendientes, un cortijo en el camino de Huétor, pago del Zaidín, que fue de Aixa, la madre de Boabdil, y que es tradición donaron los Reyes á D. Sancho de Castilla» ${ }^{65}$.

La presencia del cortijo en el siglo XIX en la misma ubicación a la que ha apuntado Pulido, respaldada por gran número de documentos citados, la preservación de la memoria familiar de la merced de los monarcas católicos y la mención de la madre de Boabdil nos obligan a pensar que necesariamente se trata de Daralgazi, o al menos de una estructura reconstruida en la misma ubicación o en un punto muy cercano. Esto nos da una imagen de la relevancia que la merced tuvo para esta rama de los Castilla para perpetuarse el recuerdo tras cuatro siglos.

Por último, volveremos la vista hacia Darabenaz. Al sur de Granada, en el actual término de La Zubia, se encuentra el Cortijo de la Marquesa en cuya estructura se detectaron los restos de una almunia nazarí. Fue tratada por Manzano Martos ${ }^{66}$ en los años sesenta y por Antonio Malpica, en los ochenta ${ }^{67}$. Nos interesa especialmente un trabajo de este último, en el cual muestra que Darabenaz pasó a formar parte de la propiedad del conde de Tendilla y que este, posteriormente, la vendería al marqués del Cenete. Lo que nos interesa, en todo caso, es la riqueza que desprenden los documentos analizados por Malpica, hablándonos de una propiedad extensa, con una gran red de acequias que propiciaba la explotación por regadío, el viñedo, la presencia de morales y olivos. A raíz del estudio de unos censos enfitéuticos de Darabenaz, muestra que el conde de Tendilla percibió casi 60.000 maravedíes de renta por poco más de 1.000 marjales del heredamiento antes de la fecha de venta al marqués del Cenete, en $1511^{68}$. Este último pagaría además por su adquisición un total de 3.750 .000 maravedíes $^{69}$-con una parte en metálico y otra a través de un juro- suma extremadamente elevada que refleja la rentabilidad y el interés de Darabenaz.

Aunque se trate de una comparación algo aventurada, equiparar Darabenaz a Daralgazi tendría sentido en cuanto a su evidente cercanía geográfica y una tipología de explotación semejante. Debemos tener en cuenta el descenso de los precios al que apuntan Molina y Mata a finales del siglo xv y que, aún así, Daralgazi bien podía rentar los

65 Durán y Lerchundi, Joaquín. La toma de Granada y caballeros que concurrieron á ella. Tomo 2. Madrid: Imprenta y Litografía de los Huérfanos, 1893, p. 493.

66 Manzano Martos, Rafael. «Darabenaz: Una alquería nazarí en la Vega de Granada». Al-Andalus, 1961, vol. 26, n. ${ }^{\circ} 1$, p. 201-218.

67 Malpica Cuello, Antonio. «Una propiedad del conde de Tendilla: Darabenaz». En Malpica Cuello, Antonio (ed.). Andalucía en el siglo XVI. Estudios sobre la tierra. Granada: Librería Al-Andalus, 1981, pp. 9-49.

68 Ibidem, pp. 22-23.

69 Ibidem, p. 27. 
40.000 maravedíes anuales entre 1494 y 1495. Darabenaz rentará 60.000 en un momento en que los precios se habían recobrado, por lo que podemos conjeturar sobre el tamaño relativo de Daralgazi respecto a esta otra almunia. Así, lo más lógico sería suponer que Daralgazi fuera un heredamiento más pequeño, o menos rentabilizado que Darabenaz, aunque no significativamente. Mientras, su estructura de almunia o núcleo principal, al contrario de lo que ocurriría en la Casa de la Marquesa, pudo perderse hacia finales del siglo XvI en vez de reintegrarse en una construcción moderna. A no ser que el cortijo del que habla Lerchundi partiera del edificio antiguo, en cuyo caso nos encontraríamos con dos casos muy semejantes entre sí.

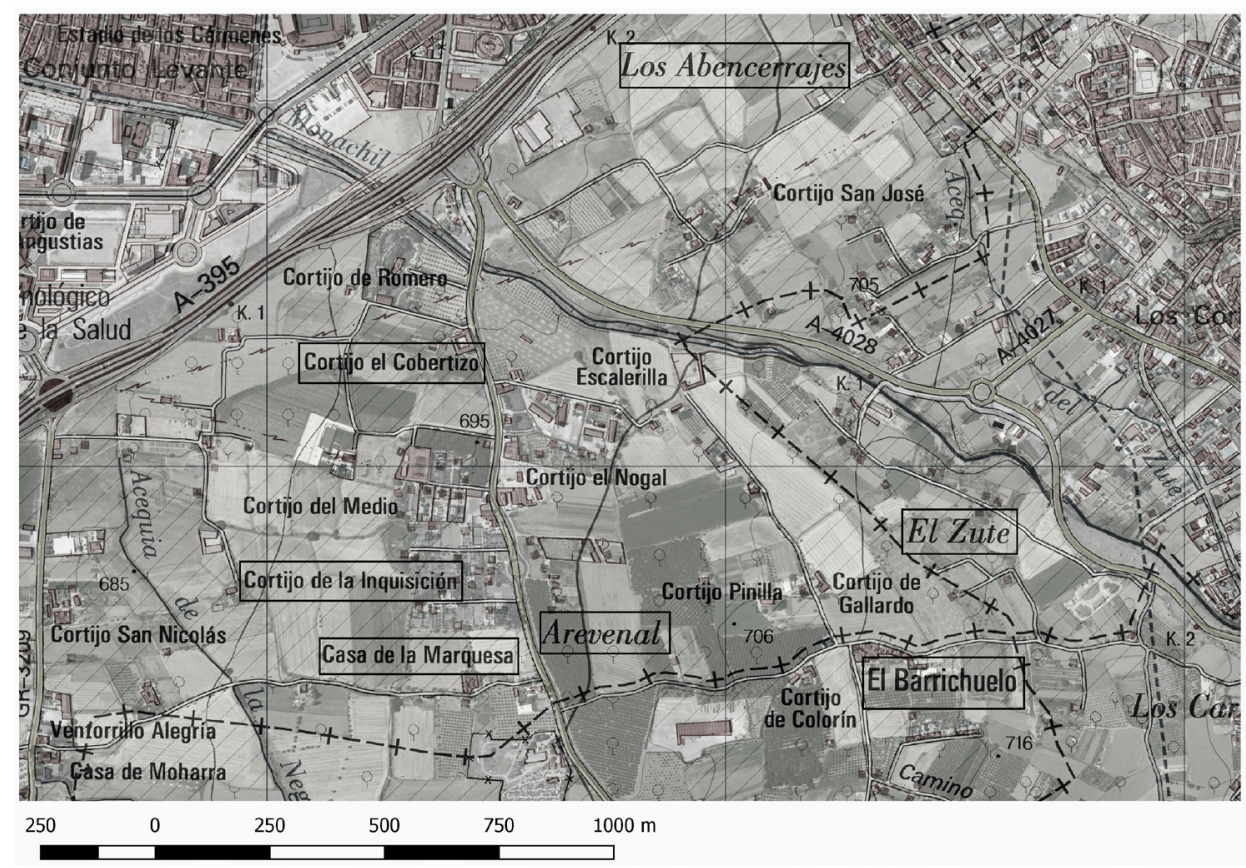

Mapa 2. Cortijos y topónimos en mapa MTN25 con ortoimagen del IGN.

\section{Conclusión}

El paso del tiempo ha borrado el nombre de Daralgazi de los mapas actuales, y no hay ninguna evidencia clara y conocida del nombre del pago tras el apeo de 1572, pero permanece el recuerdo de un cortijo de donación regia aún en el siglo xIx. Esta propiedad que una vez formó parte de los bienes de la familia real nazarí y concretamente de las «reinas moras», pasa de forma directa a otros monarcas sin mayor intervención que la del secretario Hernando de Zafra, para terminar rápidamente en manos de don Sancho de Castilla. Sin duda alguna, se muestra como un emplazamiento estrechamente vinculado 
a la realeza y aristocracia, tanto musulmana como cristiana, en un contexto convulso y cambiante como es la instauración del poder castellano en el Reino de Granada. Se trata, desde luego, de un heredamiento que sirve a los Reyes Católicos de mecanismo de recompensa o moneda de pago para retribuir todos los servicios y lealtades a don Sancho. Y así, forma parte de un amplio rango de propiedades aristocráticas que derivan en esta misma línea entre finales del siglo XV y comienzos del siglo XVI, incluyendo aquellas que, a diferencia de Daralgazi, obtienen también la jurisdicción, convirtiéndose en señorío.

El heredamiento de Daralgazi, con todos los elementos que lo componen, a pesar de no haber dejado resto material conocido, tuvo que ser de suficiente entidad como para ser citado por su nombre en las conversaciones entre la realeza nazarí y Zafra. A nuestro entender, si algún día existió una almunia en Daralgazi tuvo que estar en buenas condiciones a finales del siglo XV, con una tierra fértil, rentable y bien irrigada. Es posible que sufriera una paulatina decadencia durante las próximas décadas, hasta llegar al punto en el que se perdiera la construcción principal y quedar reducida a las "piedras» de Daralgazi. Únicamente quedaría el nombre del amplio pago que nos encontramos en el apeo, para, en un momento indeterminado, desaparecer también. El cortijo de los duques de Gor que se menciona en el siglo xIx pudo ubicarse sobre la estructura nazarí o bien en un lugar cercano, correspondiendo quizás a esa hacienda de don Sancho que se cita en el apeo, sin necesariamente identificarse con las estructuras del Cobertizo Viejo.

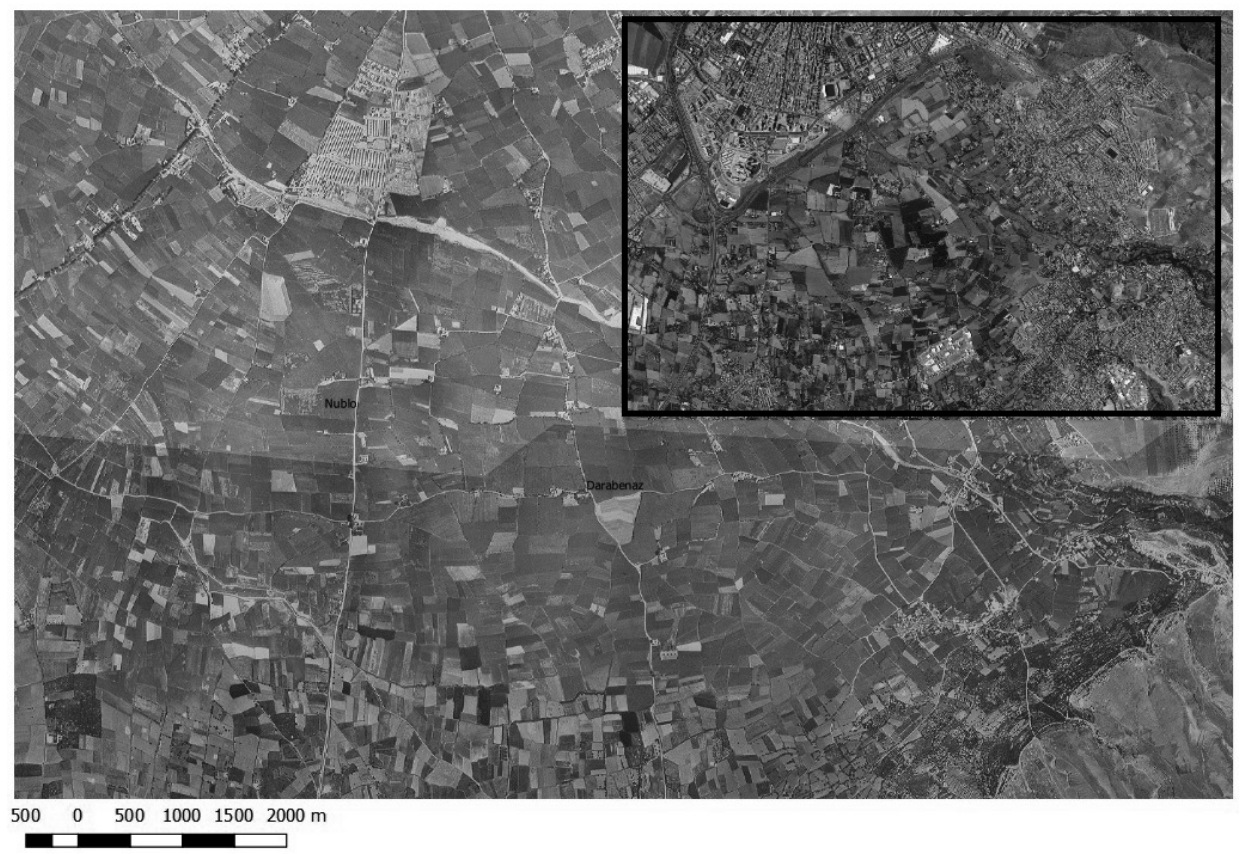

Mapa 3. Muestra del rápido crecimiento urbanístico que ha sufrido esta región de la Vega de Granada en los últimos 60 años (vuelo americano del 56/57 y actualidad). 
Creemos que la documentación aportada hasta el momento facilita el conocimiento de la ubicación de la antigua casa principal y el pago de Daralgazi, si bien solo la aparición de mapas históricos, documentos inéditos o la intervención arqueológica nos pueden arrojar nuevos datos. Se hace cada vez más evidente la necesidad de compaginar metodologías y herramientas muy distintas entre sí para obtener los mejores resultados. A pesar de ello, no podemos descartar la posibilidad de que Daralgazi se encuentre en un territorio hoy urbanizado, a raíz de los grandes cambios que ha experimentado durante los últimos cien años el extrarradio de Granada, con su Vega. Sirva, con todo, nuestro breve acercamiento para conocer algo mejor este heredamiento de tipo aristocrático. Daralgazi solo es un breve hilo en el entramado de propiedades que durante este mismo período de tiempo pasa de nobles musulmanes a castellanos, acelerando la formación de grandes haciendas, terminando en nuevos procesos de compraventa entre cristianos o perdiéndose, como en este caso, en la memoria. Siendo este entramado el objeto que ha de estudiarse en mayor profundidad durante los próximos años.

\section{ApÉNDice DocumentaL}

\section{4, mayo, 3. Medina del Campo.}

Los Reyes Católicos, don Fernando y doña Isabel, entregan a don Sancho de Castilla, capitán y maestresala del príncipe don Juan, el heredamiento de Daralgazi, situado en la Vega de Granada, a cambio de sus servicios prestados en la Guerra de Granada. Este heredamiento habia formado parte del patrimonio real nazari, y concretamente estuvo en manos de la madre de Boabdil.

Archivo General de Simancas, Cámara de Castilla, CED, 1, 39, 2.

Traslado de la carta de merçed quel Rey e la Reyna nuestros señores hizieron de Daralgasi a don Sancho de Castilla, maestresala del señor principe.

(Al margen izquierdo): Castilla. Merced de Daralgari.

Don Fernando e doña Ysabel e etc. [...] a los Reyes e prínçipes es propia cosa onrrar e sublymar e faser grasias e mersedes a los sus súbditos e naturales, espeçialmente a aquellos que bien e lealmente los syruen, lo qual por nos considerado e acatando los muchos e buenos e leales seruisios que vos, don Sancho de Castilla, nuestro capitán e maestresala del prínçipe don Juan, nuestro muy caro e muy amado fijo, nos avedes fecho e fasedes de cada día, asý en la guerra pasada de los moros enemygos de nuestra Santa Fee Católica, donde con vuestra persona continuamente, espeçial el día que nos fuymos a ver a la çibdad de Granada e se fizo el desbarato a los moros en el (Rabí), donde vos os hallastes e pusystes vuestra persona a mucho peligro peleando e nos fuystes en ello mucho, vos e la gente que debaxo de vuestra capitanýa tenýades, con otros seruisios sinalados y de vos avemos relaçión y en alguna hemienda e remuneraçión dellos vos fasemos graçia e merçed e donaçión pura e perfeta e acabada que es dicha entre biuos no reuocable, para agora e para syempre jamás, para vos e para vuestros ferederos e suçesores e para aquel o aquellos que de vos o dellos ouyeren causa o razón, en qualquier manera, de nuestro feredamyento e casa de Daralgazi, que es en térmyno e juridiçión de la nuestra çibdad de Granada, lo qual nos ouymos de la reyna mora, madre del rey Muley Baudil nuestro vasallo, al tiempo quel dicho rey e ella se fueron 
de nuestros reynos e se pasaron allende con todos ${ }^{70}$ sus térmynos e tierras destritos e terretorios que ella ay e ouiere de aquí adelante, e con las casas, huertas, corrales, viñas e tierras labradas e non labradas que son nuestras e nos pertenesçen en el dicho heredamyento y en sus térmynos e tierras; e con los prados e pastos, exidos, abreuaderos e sotos e árboles frutuosos e ynfrutuosos e montes e dehesas, ríos e molinos e fuentes e aguas corrientes, estantes e manantes e otras qualesquier cosas que a nos pertenesçen e pertenesçer pueden e deuen en qualquier manera en el dicho heredamyento e casas de Daralgasi e sus térmynos, por rasón del señorío e propiedad dél por virtud de la dicha conpra, eçebto la juridiçión, que esta quede para la çibdad de Granada; e con todas las otras cosas quantas el dicho heredamyento ha e aver puede e deue de dicho uso e costumbre del qual dicho heredamyento e rentas e pechos e derechos e otras qualesquier cosas que de suso van declaradas y espaçificadas, vos fasemos merçed graçia e donaçión para que todas las tales (rentas) e derechos e todas las otras cosas e cada una dellas de suso declaradas y espaçificadas sean vuestras e de vuestros herederos e subçesores, por juro de heredad por siempre jamás. E para que si quisiéredes lo podades dar e donar e vender e enpeñar e trocar e cambiar i enajenar e renunçiar e traspasar en parte o en todo, en qualquier tiempo que por contrato e donaçión o venta o por otra qualquier dispusiçión o qualquier o qualesquier // ( fol. 40r) persona e personas a faser dello i en ello como de cosa vuestra propia avida e adquirida por justo título e buena fee. E por la presente de oy día de la data desta nuestra carta para syempre jamás nos desapoderamos del dicho heredamyento e casa de Daralgasi e (rentas) e térmynos dél e de todas las otras cosas e de cada una dellas contenydas en esta dicha nuestra carta segund y en la manera que dicha es. E desde agora vos damos la posesyón de todo ello e de señorío e propiedad dello a vos el dicho don Sancho de Castilla, para vos e para vuestros herederos e subçesores como cosa vuestra. E vos constituymos por verdadero poseedor de todo ello para que lo ayades e poseades e sea vuestro, como dicho es. E por esta nuestra carta mandamos e damos poder a vos, el dicho don Sancho de Castilla, para que vos mysmo o quien vos quisiéredes o vuestro poder para ello ouyere por vuestra propia abdtoridad con esta nuestra carta syn otra nuestra carta ny prouysión e syn abtoriad de alcaldes ny de juezes ny de otras personas algunas e syn pena e syn calunya alguna como quesiéredes e por bien touiéredes, podades entrar e tomar e entredes e tomedes la tenençia e posesyón vel casy del dicho heredamyento e casa de Daralgasy e (rentas) e térmynos de todas las otras cosas de suso contenydas e declaradas y espaçificadas de que vos fasemos la dicha merçed e donaçión segund dicho es. E por esta dicha nuestra carta por su traslado sygnado de escriuano público mandamos al tenedero e a los caseros e renteros del dicho heredamiento e casa de Daralgazi que luego vista esta nuestra carta o el dicho su traslado sygnado de escriuano público syn otra luenga ny tardança ny dilaçión ny escusa alguna ny syn sobre ello nos requerir ny esperar otra nuestra carta ny segunda ny terçera (justo) vos resçiba e aya e tengan por señor dello, e vos apoderen en ello i vos den i entreguen la posesyón vel casy de todo ello e asý puesto vos defiendan e amparen en ella e en cada una cosa e parte dello. Otrosí que vos acudan e fagan acudir con todas las dichas rentas i cada una dellas de suso declaradas i espeçificadas de que vos fasemos la dicha merçed e donaçión desde el día de la data desta nuestra carta de merçed en adelante en cada un año para syempre jamás segund e por la forma e manera que fasta aquí los dauan e pagauan e acudían con les a la reyna mora e a las otras personas que touyeron el dicho heredamiento en tiempo que la dicha çibdad de Granada hera de moros, eçebto la dicha juridiçión, que esta queda para la dicha çibdad de Granada como dicho es e segund que a nos e a las personas que en nuestro nombre tenýa cargo de lo

70 Tachado: $\mathrm{e}$ 
resebir e cobrar e lo ouyera e deuiera ${ }^{71}$ pagar de aquí adelante, e que en ello ny en cosa alguna ny parte dello vos no ponga enbargo ny contrario alguno. E por esta dicha nuestra carta o por el dicho su traslado sygnado de escriuano público mandades al prínçipe don Juan etc. e a cada vno e qualquier dellos que vos guarden e fagan guardar esta merçed de donaçión que vos fazemos en todo e por todo segund e por la forma e manera que en esta nuestra carta se contiene e declara e para entrar e tomar e tener e continuar e defender la posesyón de todo lo susodicho, e coger e resebir e leuar los frutos e rentas dello vos de todo el fauor e ayuda que les pudieredes e menester touyeredes fasta tanto que realmente // (fol. $40 v$ ) i con efecto seáys entregado e apoderado de todo ello como de cosa vuestra e verdadero poseedor. E quen ello ny en parte dello enbargo ny contrario alguno vos no pongan ny consyentan poner, lo qual todo queremos e mandamos que asý vos sea complido e guardado, no enbargante qualesquier ley e ordenamyentos e pramáticas sençiones que en contrario sean o (se) puedan en qualquier manera con las cuales de nuestro propio motiuo e çierta çiençia e poderío real absoluto de que en esta parte usamos aviéndolas aquí por ynsertas e yncorporadas a quanto atañe a la validaçión desta dicha merçed e donaçión que vos fasemos, e de las cosas en esta carta contenydas dispensamos con ellas e con cada una dellas quedando en su fuerça e vigor para adelante. E por esta dicha nuestra carta mandamos a los nuestros contadores maiores e a sus logartenientes que asienten en los nuestros libros e nóminas de lo saluado el traslado desta nuestra carta e vos la sobrescriuan e den (e tomen) esta otra sinal para que vos por virtud della tengades e poseades e gozedes del dicho heredamiento e casa de Daralgasi i de todas las otras cosas en ella contenydas. E que si menester fuere e vos quisiéredes nuestra carta de seruisio, mandamos al nuestro chançiller e notario i escriuanos maiores de los nuestros preuilegyos e confirmaçiones e a los otros oficios que están a la tabla de los nuestros sellos, que vos la den e libren e pasen e sellen e los vnos ny los otros etc. Dada en la villa de Medina del Campo a tres días del mes de mayo, año del nasçimiento del nuestro Saluador Ihesuchristo de myll e quatroçientos i noventa e cuatro annos. Yo el Rey; yo la Reyna; yo Fernand Áluares de Toledo, secretario del rey e de la reyna nuestros señores, la fise escriuir por su mandado acordada e en forma; Rodericus, doctor (rúbrica).

\section{REFERENCIAS BIBLIOGRÁFICAS}

Álvarez de Cienfuegos, Isabel. «La Hacienda de los nasríes granadinos». Miscelánea de Estudios Árabes y Hebraicos, 1959, vol. VIII, pp. 99-144.

Álvarez García, José Javier y García Porras, Alberto. «La zawiya del “cobertizo viejo” (Granada)». Anuario Arqueológico de Andalucía 2003, 2006, vol. 3, n.o 1, pp. 429-436.

Durán y Lerchundi, Joaquín. La toma de Granada y caballeros que concurrieron á ella. Tomo 2. Madrid: Imprenta y Litografía de los Huérfanos, 1893.

FABIÉ, Antonio (trad. y ed.). Viajes por España de Jorge de Einghen, del Baron de Rosmithal de Blatna, de Francisco Guiccardini y de Andrés Navajero. Madrid: Librería de los bibliófilos, 1879.

Fernández de Oviedo, Gonzalo. Libro de la Cámara Real del príncipe don Juan, oficios de su casa y servicio ordinario, ed. de Santiago Fabregat Barrios. València: Publicacions de la Universitat de València, 2006.

Francisco Olmos, Jose María. El principe heredero en las coronas de Castilla y Aragón durante la Baja Edad Media. Madrid: Universidad Complutense de Madrid, 2005.

71 Repetido: deuiera 
EL HEREDAMIENTO DE DARALGAZI: UNA PROPIEDAD ARISTOCRÁTICA EN LA VEGA DE GRANADA SANDRA SUÁREZ GARCÍA

\section{8}

García Pedraza, Amalia. «La asimilación del morisco don Gonzalo Fernández el Zegrí: edición y análisis de su testamento». Al-Qantara: Revista de Estudios Árabes, 1995, vol. 16, pp. 41-58.

García Pulido, Luis José. «Sobre el emplazamiento de los restos arqueológicos de la Casa de las Gallinas». Al-Qantara: Revista de Estudios Árabes, 2007, vol. 28, n.o 1, pp. 229-259.

Garrido Atienza, Miguel. Las capitulaciones para la entrega de Granada. Granada: Paulino Ventura Traveset, 1910.

Garzón Pareja, Manuel. «Señoríos del reino de Granada». Boletín de la Real Academia de la Historia, vol. CLXXIV, 1977, p. 588.

Gaspar Remiro, Mariano. "Partida de Boabdil allende con su familia y principales servidores». Revista del Centro de Estudios Históricos de Granada y su Reino, 1912, vol. 2, pp. 57-111.

Gómez Llorente, Manuel. «Los señoríos en el Reino de Granada: el señorío de Gor». Cuadernos de Estudios Medievales y Ciencias y Técnicas Historiográficas, 1985-1987, vol. XIV-XV, pp. 61-74.

González Martín, Carlos; Buendía Moreno, Antonio y Aznar Pérez, Juan Carlos. «Darabenaz, una alquería compleja. Avance de los resultados de las intervenciones arqueológicas». Estudios sobre Patrimonio, Cultura y Ciencias Medievales, 2015, vol. 17, pp. 161-180.

Hernández Benito, Pedro. La Vega de Granada a fines de la Edad Media según las rentas de los habices. Granada: Diputación Provincial de Granada, 1990.

IвN AL Jатів. Historia de los Reyes de la Alhambra: el resplandor de la luna llena acerca de la dinastía nazari (Al-Lamba al-badriyya fi l-dawlat al nastiyya). Trad. de Emilio Molina López y María Casciaro Ramírez. Granada: Universidad de Granada, 2010.

Iвn AL-Jatib. al-Ihāṭa fì tārīj Garnāṭ. Tomo 2. Inan, 'Abd Allah (ed.). El Cairo, 1955.

Jiménez Mata, María del Carmen. La Granada islámica. Contribución a su estudio geográficopolitico-administrativo a través de la toponimia. Granada: Universidad de Granda, 1987.

Juez Jarros, Francisco. Simbolos de poder en la arquitectura de al-Andalus. Tomo 1. Madrid: Universidad Complutense de Madrid, 1999.

Ladero Quesada, Miguel Ángel. «El duro fisco de los emires». Dos temas de la Granada nazarí, Cuadernos de Historia, anexo de Hispania, 1969, vol. 3, pp. 320-346.

Ladero Quesada, Miguel Ángel. Hernando de Zafra, secretario de los Reyes Católicos. Madrid: Dykinson, 2005.

Las Heras, Isabel; Fauve, María de y Forteza, Patricia de. "Consolidación de un linaje castellano en tiempos de los Reyes Católicos. El caso de Sancho el Ayo". En Siegrist, Nora y Zapico, Hilda (eds.). Familia, descendencia y patrimonio en España e Hispanoamérica, siglos XVI y XIX. 1. a ed. Mar del Plata: Editorial de la Universidad Nacional de Mar del Plata, 2010, p. 36.

López de Coca CASTAÑer, José Enrique. «Granada en el siglo Xv: Las postrimerías nazaríes a la luz de la probanza de los infantes don Fernando y don Juan». En Cabrera Muñoz, Emilio (coord.). Andalucia entre Oriente y Occidente (1236-1492). Actas del V Coloquio Internacional de Historia Medieval de Andalucía. Córdoba: Diputación de Córdoba, 1988, pp. 599-641.

López de Haro, Alonso. Nobiliario genealógico de los Reyes y títulos de España. Madrid: Luis Sánchez, impresor real, 1622.

Malpica Cuello, Antonio. «Las salinas de Motril. Aportación al estudio de la economía salinera del Reino de Granada a raíz de su conquista». Baetica. Estudios de Arte, Geografía e Historia, 1981, vol. 4, pp. 147-165.

Malpica Cuello, Antonio. «Una propiedad del conde de Tendilla: Darabenaz». En Malpica Cuello, Antonio (ed.). Andalucía en el siglo XVI. Estudios sobre la tierra. Granada: Librería Al-Andalus, 1981, pp. 9-49.

Malpica Cuello, Antonio y Trillo San José, Carmen. «Los infantes de Granada. Documentos árabes romanceados». Revista del Centro de Estudios Históricos de Granada y su Reino, 1992, vol. 6, pp. 361-375. 
EL HEREDAMIENTO DE DARALGAZI: UNA PROPIEDAD ARISTOCRÁTICA EN LA VEGA DE GRANADA SANDRA SUÁREZ GARCÍA

Manzano Martos, Rafael. «Darabenaz: Una alquería nazarí en la Vega de Granada». Al-Andalus, 1961, vol. 26, n. ${ }^{\circ} 1$, p. 201-218.

Martínez Vázquez, Luis. La Vega de Granada. Transformación y cambio de los paisajes entre el Reino Nazari y el Reino de Granada. Granada: Universidad de Granada, 2015.

Matarín Guil, Manuel Francisco. "Los Castilla, señores jurisdiccionales de la taha de Boloduy». En Andújar Castillo, Francisco y Díaz López, Pablo (coords.). Los señorios en la Andalucía Moderna. El Marquesado de los Vélez. Almería: Instituto de Estudios Almerienses, 2007, pp. $505-522$.

Molina López, Emilio y Jiménez Mata, María del Carmen. «La propiedad de la tierra en la Vega de Granada a finales del siglo xv. El caso de Alitaje». Anaquel de Estudios Árabes, 2001, vol. 12, pp. 449-480.

Molina López, Emilio. «El mustajlas andalusí (I) (s. viII-XI)». Revista del Centro de Estudios Históricos de Granada y su Reino, 1999-2000, vol. 13-14, pp. 99-189.

Narganes Quijano, Faustino. "Acerca de los primeros corregidores en Palencia (ss. XV-Xvi)». Publicaciones de la Institución Tello Téllez de Meneses, 1993, vol. 64, pp. 597-610.

Oliver Hurtado, José y Oliver Hurtado, Manuel. Granada y sus monumentos árabes. Málaga: Imprenta de M. Oliver Navarro, 1875.

Padilla Mellado, Lorenzo. Libro del apeo y deslinde del Pago del Zaidín y Daralgazi. Año de 1572 (Traslado del original). Granada: Universidad de Granada, 2017.

Peinado Santaella, Rafael. «El patrimonio real nazarí y la exquisitez defraudatoria de los "principales" castellanos». Medievo Hispano: Estudios in memoriam del prof. Derek W. Lomax. Madrid: Sociedad Española de Estudios Medievales, 1995, pp. 297-318.

Peinado Santaella, Rafael. «Un espacio aristocrático: propiedad y poblamiento en el sector occidental de la Vega de Granada a finales de la Edad Media». Fundamentos de Antropología, 1997, vol. 6-7, pp. 232-244.

Pulgar, Hernando del. Crónica de los señores Reyes Católicos Don Fernando y Doña Isabel de Castilla y de Aragón. Valencia: Imprenta de Benito Monfort, 1780.

Salvá, Miguel y Sainz de Baranda, Pedro. Colección de documentos inéditos para la Historia de España. Tomo XI. Madrid: Imprenta de la viuda de Calera, 1847.

Soria Mesa, Enrique. «De la conquista a la asimilación. La integración de la aristocracia nazarí en la oligarquía granadina. Siglos Xv-XvII». Áreas. Revista de Ciencias Sociales, 1992, vol. 14, pp. 49-64.

Soria Mesa, Enrique. «Entre reyes moros y oscuros labradores cristianos. Un itinerario familiar morisco: los Granada Venegas de Monachil (siglos XVI-XVIII)». En Titos Martínez, Manuel (coord.). Monachil. Historia de un pueblo de la sierra. Monachil: Ayuntamiento de Monachil, 1995.

Soria Mesa, Enrique. «La venta de bienes de la casa real. El caso de Gor bajo Muhammad IX 'El Izquierdo'». Miscelánea de Estudios Árabes y Hebraicos, 1993-1994, vol. 42-43, n. o 1, pp. 291-304.

Soria Mesa, Enrique. Señores y oligarcas: los señorios del Reino de Granada en la Edad Moderna. Granada: Universidad de Granada, 1997.

SuÁrez García, Sandra. "Los habices de la Vega de Granada como forma de conocimiento del reino nazarí y su transformación tras la conquista: La alquería de La Zubia». Espacio, Tiempo y Forma. Serie III, Historia Medieval, 2018, vol. 31, pp. 641-667.

Torres Balbás, Leopoldo. «Las alhóndigas hispanomusulmanas y el Corral del Carbón de Granada». Al-Andalus, 1946, vol. XI, pp. 219-266.

Trillo SAN José, Carmen. «El Nublo, una propiedad de los infantes de Granada». En Homenaje al profesor José María Fórneas Besteiro. Granada: Universidad de Granada, 1995, vol. 2, pp. 867-879. 
Trillo SAN José, Carmen. «Hornos de pan en la ciudad de Granada: precedentes nazaríes y transformaciones castellanas». En Marín López, Rafael (ed.). Homenaje al Profesor Dr. D. José Ignacio Fernández de Viana Vieites. Granada: Universidad de Granada, 2012, pp. 615629.

TrILlo SAN JosÉ, Carmen. «Les munya-s et le patrimoine royal à l'epoque nasride ( $\mathrm{XIII}^{\mathrm{e}}-\mathrm{XV}^{\mathrm{e}}$ siècles). Entre le souverain et les élites». Annales Islamologiques, 2014, vol. 48, n.o 2, pp. 167-190.

Trillo San José, Carmen y Navarro Palazón, Julio (eds.). Almunias del Occidente islámico: solaz y producción. Granada: Universidad de Granada (en prensa).

Villanueva Rico, María del Carmen. Casas, mezquitas y tiendas de los habices de las iglesias de Granada. Madrid: Instituto Hispano-Árabe de Cultura, 1966. 